\title{
DETERMINASI PENDIDIKAN AGAMA ISLAM DAN POLA ASUH DEMOKRATIS TERHADAP AKHLAK REMAJA
}

\author{
Abidatul Mardliyah \\ Institut Agama Islam Bani Fattah Jombang, Indonesia \\ royabidah@gmail.com
}

\begin{abstract}
This study aims to determine the relationship between Islamic religious education and democratic parenting style with adolescent morals. The subjects of this study were 79 adolescents living in Sumbermulyo, Jogoroto, Jombang Regency. To obtain data on the relationship between Islamic Religious Education and democratic parenting style with adolescent morals, a questionnaire compiled by the researcher was used. To achieve this goal, the data were analyzed by means of regression analysis, as well as by observations and some existing data and documents.

Based on the results of data analysis, obtained $t$ count of 5.636 when referred to the value of $t$ table at the significance level of $5 \%$ obtained t table value of 1.67 so that $t$ count is greater than $\mathrm{t}$ table $(5.636>1.67)$, then the results are significant. Thus it can be concluded that, (1) there is a significant positive influence between Islamic Religious Education on adolescent morals in the community of Sumbermulyo, Jogoroto, Jombang Regency; (2) there is a positive effect of democratic parenting on adolescent morals Keywords: Islamic religious education, democratic parenting, adolescent morals
\end{abstract}




\section{PENDAHULUAN}

Pendidikan Agama Islam adalah suatu sistem pendidikan yang memungkinkan seseorang dapat mengarahkan kehidupannnya sesuai dengan cita-cita Islam, sehingga dengan mudah ia dapat membentuk hidupnya sesuai dengan ajaran Islam. ${ }^{1}$ Sejalan dengan pemikiran AsySyaibany yang mengemukakan bahwa pendidikan agama islam merupakan proses mengubah tingkah laku individu pada kehidupan pribadi, masyarakat, dan alam sekitarnya, dengan cara pengajaran sebagai suatu aktivitas asasi dan sebagai profesi di antara profesi-profesi asasi dalam masyarakat. ${ }^{2}$

Pengertian tersebut menfokuskan perubahan tingkah laku manusia yang konotasinya pada pendidikan etika. Selain itu, pengertian tersebut menekankan pada aspek-aspek produktivitas dan kreativitas manusia dalam peran dan profesinya dalam kehidupan dalam masyarakat dan alam semesta.

Pendidikan yang merupakan institusi bagi peningkatan kualitas hidup manusia, malah membawa petaka akhlak pada bangsa. Fakta menyebutkan bahwa tingginya angka pelanggaran akhlak di kalangan para remaja dan para pelajar, baik yang melakukan seks bebas, narkoba, pencurian, pembunuhan, pemerkosaan, pelanggaran lalu lintas, penipuan hingga membohongi orang tua, bahkan sampai perjudian pun di lakukan. Lebih ironis lagi, mereka merasa bangga dengan apa yang di lakukan padahal mereka tahu kalau apa yang mereka lakukan adalah perbuatan yang salah. Ada apa dibalik semua kejadian itu? Apa sudah tidak ada lagi pemahaman tentang apa yang telah mereka dapat di sekolah? Apa yang salah dari pendidikan di negara ini yang seharusnya bertujuan mencetak generasi yang berakhlaqul karimah malah membawa petaka akhlak pada generasi bangsa. Memang ada gejala kuat bahwa sekolah telah jauh bergeser menjadi hanya sebatas pasar ilmu dan bank soal ujian, sehingga remaja hanya ditawari, dijejali, disuguhi sampah ilmu dan bank soal ujian, banyak sekali sekolah dan guru yang tidak berfikir akhlak dan budi pekerti atau akhlak siswa sehebat pikiran untuk mencapai angka UAN yang tinggi. Inilah akar-akar yang tampak, untuk kehancuran bangsa Indonesia. ${ }^{3}$

Setiap orang tua pasti menginginkan remajanya sukses dikemudian hari, baik dalam pendidikan, keluarga, dan ekonominya. Dan salah satu hal terpenting yang diinginkan oleh orang tua adalah keberhasilan kepribadiannya, oleh sebab itu mendidik remaja dengan sebaik-baiknya

\footnotetext{
${ }^{1}$ Bukhari Umar, Ilmu Pendidikan Islam, (Jakarta: AMZAH, 2010), Cet. I, hlm 27 ${ }^{2}$ Ibid.,

${ }^{3}$ Mursidin, Akblak. Sumber Pendidikan, edtr. Komarudin (Bandung : PT Ghalia Indonesia, 2011) hlm.5
} 
diperlukan untuk membentuk pribadi remaja yang baik. Seperti yang dikatakan Robert Fulghum

"Jangan mengkuatirkan babwa remaja-remaja tidak mendengarkan Anda, kuatirkanlab bahwa mereka selalu mengamati Anda".Pendidikan dalam keluarga yang baik dan benar, akan berpengarub dalam pembentukan pribadi remaja. Kebutuban yang diberikan melahi pola asub orang tua akan memberikan kesempatan pada siremaja untuk menunjukekan bahwa dirinya adalab bagian dari lingkungan sekitar. ${ }^{4}$

Dewasa ini sering kita saksikan tindakan kriminal atau perilakuperilaku menyimpang baik itu di siaran televisi, Koran, radio, media massa dan lain sebagainya. Sebagian besar pelakunya adalah dari kalangan remaja. Seperti kasus tawuran antar pelajar, miras, obat-obatan terlarang, bahkan pembunuhan bermotif dendam atau kecemburuan. Masih hangat ditelinga kita tentang berita LGBT dimana grup ini menaungi semua pasangan lesbian dan gay seluruh dunia dan memiliki tingkatan dari mulai tingkat SD sampai dewasa. Sungguh ironis jika remaja-remaja kita juga mengikuti hal semacam itu, Padahal remaja itu masih dalam tahap perkembangan menjadi pubertas atau katakan saja masih bayi, bayi yang baru lahir ke dunia ini belum mengenal apapun, ia masih bersih dan murni dan belum terpengaruh sedikitpun oleh suatu hal. Bagaimana perkembangan bayi selanjutnya agar menjadi remaja yang baik? Dalam hal ini orang tualah yang berperan penting terhadap pertumbuhan dan perkembangan bayi. Dan yang lebih penting lagi adalah cara bagaimana orang tua mendidik remajanya. Apakah pola yang mereka gunakan itu tepat? Masalah ini harus benar-benar diperhatikan oleh orang tua, karena penerapan pola asuh terhadap remaja sangat berpengaruh pada perkembangan pribadi remaja.

Pendidikan akhlak merupakan faktor yang sangat penting dalam membangun akhlak remaja. Di dalam al-qur'an terdapat perilaku (akhlak) terpuji yang hendaknya di aplikasikan oleh umat manusia dalam kehidupan sehari-hari, karena akhlak mulia merupakan barometer terhadap kebahagiaan, keamanan, ketertiban, dalam kehidupan manusia dan dapat dikatakan bahwa akhlak merupakan tiang berdirinya umat, sebagaimana shalat sebagai tiang agama Islam. Dengan kata lain apabila rusak akhlak suatu umat maka rusaklah bangsanya. Keluarga yang tidak dibangun dengan tonggak akhlak mulia tidak akan dapat hidup bahagia sekalipun kekayaan materialnya melimpah ruah. "pendidikan akhlak di

\footnotetext{
${ }^{4}$ Hidayah, Nur., Pengaruh Pola Asub Orang Tua Terbadap Pembentukan Kepribadian(Jakarta: Bumi Aksara,2012) hlm.8
} 
dalam keluarga dilaksanakan dengan contoh dan teladan dari orang tua dalam hubungan dan pergaulan antara ibu dan bapak, perlakuan orang tua terhadap remaja-remaja mereka, dan perlakuan orang tua terhadap orang lain di dalam lingkungan keluarga dan lingkungan masyarakat, akan menjadi teladan bagi remaja-remaja". Seseorang akan dinilai bukan karena jumlah materinya yang melimpah, ketampanan wajahnya dan bukan pula karena jabatannya yang tinggi. Allah SWT akan menilai hamba-Nya berdasarkan tingkat ketakwaan dan amal baik (akhlak baik) yang dilakukan.

Zaman sekarang ini akhlak mulia adalah hal yang mahal dan sulit diperoleh, kemerosotan akhlak terjadi akibat adanya dampak negatif dari kemajuan di bidang teknologi yang tidak diimbangi dengan keimanan dan telah menggiring manusia kepada sesuatu yang bertolak belakang dengan nilai Al- Qur'an. Seperti halnya sabda Rasululloh SAW tentang perintah berakhlaqul karimah,sebagai berikut :

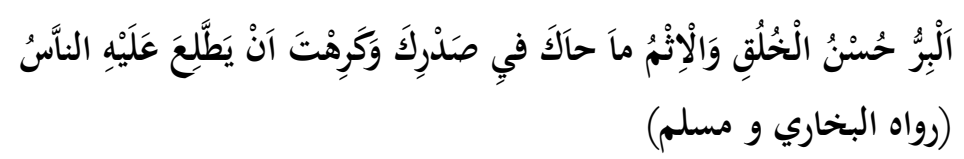

"Perbuatan yang baik itu adalah merupakan akblak yang baik. Sedangkan perbuatan dosa itu adalab apa -apa yang menggoncangkan hatimu(jiwamu) yang kamu benci dilihat hal ituoleb orang lain." (HR.Muslim) ${ }^{6}$

Memiliki akhlak yang mulia sesuai dengan tuntunan Al- Qur'an mestilah berpedoman pada Rasululloh SAW karena beliau memiliki sifatsifat terpuji yang harus dicontoh dan menjadi panduan bagi umatnya. Nabi SAW adalah orang yang kuat imannya, berani, sabar, dan tabah dalam menerima cobaan. Beliau memiliki akhlak yang mulia, oleh karenanya beliau patut ditiru dan dicontoh dalam segala perbuatannya. Allah SWT memuji akhlak nabi SAW dan mengabadikannya dalam ayat Al-Qur'an yang berbunyi sebagai berikut :

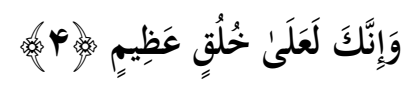

"Dan Sesunggubnya kamu benar-benar berbudi pekerti yang agung." (QS. Al- qalam(68):4)

\footnotetext{
${ }^{5}$ Zakiah Daradjat,Pendidikan Islam Dalam Keluarga dan Sekolah,(Jakarta : Ruhama, 1995), Cet. II, hlm 60

'Wajidi Sayadi, Hadits Tarbawi,(Jakarta: PT. Pustaka Firdaus.2009), hlm.53

${ }^{7}$ Depag RI, Al-Qur'an Dan Terjemahnya,(Jakarta: PT. Qomari Prima.2002), hlm.960
}

4 Muróbbî: Jurnal Ilmu Pendidikan 
Rasulullah SAW juga memiliki misi yang tertuang pada hadits yang diriwayatkan Bukhori Muslim, Rasulullah bersabda :

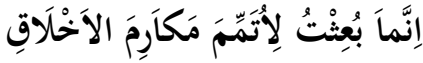 \\ "Sesunggubnya aku di utus ke muka bumi ini adalab untuk menyempurnakan akblak manusia "(HR.Bukhori-Muslim) ${ }^{8}$}

Fenomena yang terjadi pada saat ini merupakan tugas kita semua tidak hanya di bebankan kepada guru di sekolah-sekolah saja tetapi juga kewajiban bagi orang tua, masyarakat khususnya di lingkungan desa sumbermulyo sebagai tempat untuk pengambilan sampel penelitian yang di lakukan oleh penulis, lebih-lebih seorang guru agama yang di harapkan dengan ajaran - ajaran agama dapat menumbuhkan lagi pola pendidikan berakhlak yang tidak hanya menuntut suatu nilai angka pencapaian prestasi remaja, tetapi juga mementingkan tentang nilai akhlak sebagai penyeimbangnya, agar remaja dapat mencapai tujuan pendidikan yang sesungguhnya yakni menjadi insan kamil .

Penulis memilih Desa Sumbermulyo Kecamatan Jogoroto Kabupaten Jombang sebagai tempat untuk pengambilan sampel penelitian karena penulis sering sekali mendengar berita bahwa Desa Sumbermulyo Kecamatan Jogoroto Kabupaten Jombang beberapa anggota masyarakatnya melakukan tindakan kriminalitas padahal pada lingkungan Desa Sumbermulyo Kecamatan Jogoroto Kabupaten Jombang terdapat beberapa lembaga pendidikan khususnya pendidikan Agama Islam baik yang formal maupun non formal,dan penulis juga sering mendengar cerita remaja-remaja dilingkungan desa sumbermulyo tentang hal-hal yang secara masyarakat umum merupakan tindakan kriminalitas dan menyimpang moral, namun remaja-remaja tersebut tidak memahami bahwa yang mereka lakukan adalah salah karna dari keluarga khususnya orang tua tidak mengajarkan hal demikian dan terkesan lebih acuh terhadap tumbuh kembang remaja,mereka sibuk dengan profesi masing-masing dan hanya mempercayakan pendidikan remaja-remaja mereka pada suatu lembaga pendidikan padahal waktu remaja-remaja lebih panjang dirumah dimana mereka juga sangat membutuhkan perhatian dan pengawasan orang tua.

Melihat fenomena yang terjadi penulis menjadi tertarik untuk melakukan sebuah penelitian tentang determinasi pendidikan agama dan pola asuh orang tuademokratis terhadap akhlak remaja.

${ }^{8}$ Wajidi Sayadi, Hadits Tarbawi,(Jakarta: PT. Pustaka Firdaus.2009) 


\section{METODE PENELITIAN}

Dalam penelitian ini penulis menggunakan penelitian lapangan dengan pendekatan kuantitatif. Penelitian lapangan sendiri diartikan sebagai penelitian yang datanya di peroleh dengan cara mengumpulkan dari pengalaman empiris di lapangan atau kancah penelitian.

\section{Tempat dan Waktu Penelitian}

Penelitianinidilaksanakan di Desa Sumbermulyo Kecamatan Jogoroto Kabupaten Jombang.

\section{Populasi dan Sampel}

Populasidalam penelitian ini adalah, remaja pada usia 12-15 tahun(tingkat SMP), orang tua remaja yang berjumlah 790 remaja dari 6 dusun yang ada di desa Sumbermulyo.Selanjutnya penelitimegambil sampel sebanyak 10\% dari jumlah populasi sebanyak 790 mendapat hasil sampel sebanyak 79 remaja. ${ }^{9}$

\section{Analisis Data Penelitian}

Analisis data kuantitatif bertujuan untuk mempermudah memahami apa yang terdapat di balik semua data tersebut, mengelompokannya, meringkasnya menjadi suatu yang kompak dan mudah dimengerti, serta menemukan pola umum yang timbul dari data tersebut. Dalam analisis data kuantitatif, agar mudah dimengerti dan pola umum itu terwakili dalam bentuk simbol-simbol statistik, yang dikenal dengan istilah notasi, variasi, dan koefisien. Seperti rata-rata $(\mathrm{u}=\mathrm{miu})$, jumlah $\left(\sum=\right.$ sigma $)$, taraf signifikansi $(\alpha=$ alpha $)$, koefisien korelasi $(\mathrm{p}=$ rho), dan sebagainya. ${ }^{10}$

Dalam menganalisa data analisis strukturalistik (kuantitatif) hendaknya konsisten dengan paradigma, teori dan metode yang dipakai dalam penelitian. Ada perbedaan analisa data dalam analisis penelitian kuantitatif dan kualitatif. Dalam penelitian kuantitatif, analisa data yang dilakukan secara kronologis setelah data selesai dikumpulkan semua dan biasanya diolah dan dianalisis dengan secara computerizedberdasarkan metode analisi data yang telah ditetapkan dalam desain penelitian. Adapun teknik pengumpulan data yang sering digunakan seperti; tes tertulis, pengisian angket, observasi, dan wawancara langsung. ${ }^{11}$

Dalam menganalisa data penelitian peneliti menggunakan SPSS 19 dan menggunakan rumus regresi ganda untuk variabel yang

\footnotetext{
9Sugiyono, Metode Penelitian Kualitatif, Kuantitatif, R\&D, (Bandung: Alfabeta, 2016), 13

${ }^{10}$ Bambang Prasetyo, Metode Penelitian Kuantitatif, Jakarata: PT Raja Grafindo Persada, 2008

${ }^{11}$ M. Kasiram, Metodologi Penelitian Pendidikan, Jakarta: Rineka Cipta, 2006
}

6 Muróbbî: Jurnal Ilmu Pendidikan 
berpengaruh secara silmultan dilanjut korelasi parsial untuk setiap variabel yang berpengaruh secara parsial. ${ }^{12}$

\section{Uji Asumsi \\ Multikolinearitas}

Uji multikolinearitas adalah untuk melihat ada atau tidaknya korelasi yang tinggi antara variabel-variabel bebas dalam suatu model regresi linear berganda. Jika ada korelasi yang tinggi di antara variabelvariabel bebasnya, maka hubungan antara variabel bebas terhadap variabel terikatnya menjadi terganggu.

Salah satu persyaratan dalam analisis regresi ganda adalah Multikolinieritas. Multikolinieritas adalah tidak adanya hubungan yang linier antara variabel independen. Jika terdapat hubungan linier antar sesama variabel independen maka dapat dikatakan model terkena masalah multikolinier. Jika terjadi hubungan antar sesama variabel independen maka variabel ini tidak orthogonal. variabel orthogonal adalah variabel independen yang nilai korelasi antar independen sama dengan nol. ${ }^{13}$

Coefficients $^{\mathrm{a}}$

\begin{tabular}{|c|c|c|c|c|c|c|c|}
\hline \multirow[t]{2}{*}{ Model } & \multicolumn{2}{|c|}{$\begin{array}{c}\text { Unstandardized } \\
\text { Coefficients }\end{array}$} & \multirow{2}{*}{$\begin{array}{c}\text { Standar } \\
\text { dized } \\
\text { Coeffic } \\
\text { ients } \\
\text { Beta }\end{array}$} & \multirow[t]{2}{*}{$\mathrm{t}$} & \multirow[t]{2}{*}{ Sig. } & \multicolumn{2}{|c|}{$\begin{array}{l}\text { Collinearity } \\
\text { Statistics }\end{array}$} \\
\hline & B & $\begin{array}{l}\text { Std. } \\
\text { Error }\end{array}$ & & & & $\begin{array}{l}\text { Toler } \\
\text { ance }\end{array}$ & VIF \\
\hline (Constant) & 68,763 & 9,667 & & 7,113 &, 000 & & \\
\hline $\begin{array}{l}\text { PAI } \\
\text { POLA ASUH }\end{array}$ & ,308 & ,055 & ,497 & 5,636 & ,000 & 999, & 1,001 \\
\hline $\begin{array}{l}\text { DEMOKRA } \\
\text { TIS }\end{array}$ & ,237 & ,050 & ,418 & 4,736 & ,000 & 999, & 1,001 \\
\hline
\end{tabular}

a. Dependent Variable: AKHLAK

Dari data di atas dapat peneliti lihat apakah terjadi multikolinieritas pada antar variabel ataukah tidak. Agar dalam menganalisa lebih mudah peneliti menggunakan kriteria pengujian sebagai berikut: Apabila nilai VIF $<10$ maka tidak terjadi multikolinieritas Apabila nilai VIF $>10$ maka terjadi multikolinieritas

${ }^{12}$ Syofian, statistike parametrik untukpenelitian kuantitatif, Jakarta: Bumi Aksara, 2016 ${ }^{13} \mathrm{Ibid}$, 
Data diatas menunjukkan bahwa nilai VIF 1,001<10 maka dapat ditarik kesimpulan bahwa tidak terjadi multikolinieritas dalam artian analisis ini bebas dari multikolinieritas.

\section{Heteroskedasitas}

Dalam persamaan regresi berganda perlu diuji menegnai sama atau tidaknya varian dari residual dari observasi yaang satu dengan observasi yang lain.Jika residual mempunyai varian yang sama disebut terjadi homoskedasitas. Persamaan regresi yang baik adalah jika tidak terjadi heteroskedasitas.Homoskedasitas terjadi jika pada scatterplot titik titik hasil pengolahan data antara ZPRED dan ZRESID menyebar di bawah ataupun di atas titik origin (angka 0)pada sumbu $\mathrm{Y}$ dan tidak mempunyai pola yang teratur

Heteroskedasitas terjadi jika scatterplot titik-titiknya mempunyai pola yang teratur baik menyempit, melebar maupun bergelombang .

\section{Grafik Histpogram Hasil Uji Normalitas}

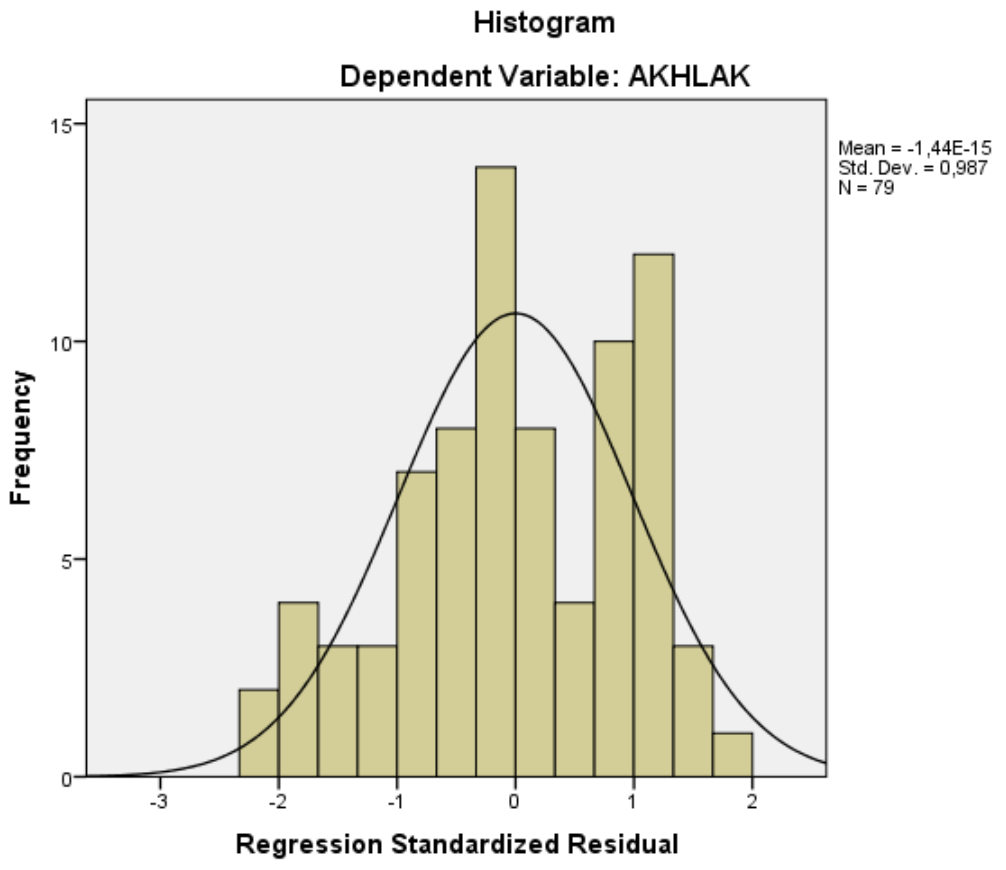




\section{Hasil Uji Heteroskedastisitas Pada Scatterplot}

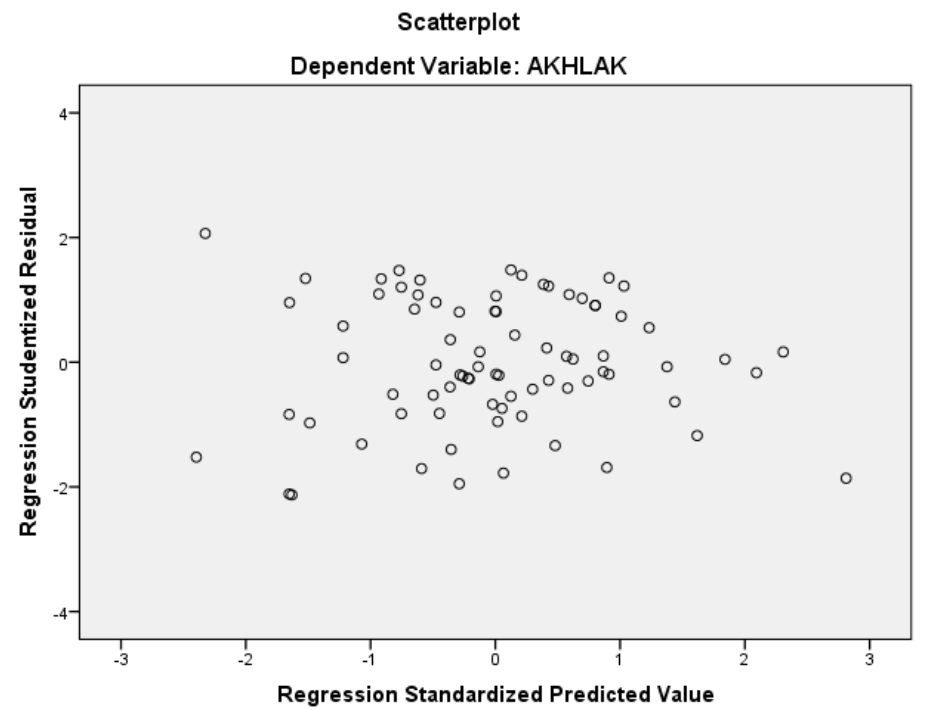

Berdasarkan gambar di atas nampak bahwa titik titik tersebar antara sumbu nol (origin) dan tidakmembentuk pola teraturyang membuktikan bahwa dalam regresi tidak terjadi heteroskedasitas

\section{HASIL PENELITIAN}

Dalam menganalisa data penelitian peneliti menggunakan SPSS 19 dan menggunakan rumus regresi ganda untuk variabel yang berpengaruh secara silmultan dilanjut korelasi parsial untuk setiap variabel yang berpengaruh secara parsial. ${ }^{14}$

ANOVA $^{\mathrm{a}}$

\begin{tabular}{|l|r|r|r|r|r|}
\hline Model & \multicolumn{1}{|c|}{$\begin{array}{c}\text { Sum of } \\
\text { Squares }\end{array}$} & df & \multicolumn{1}{c|}{$\begin{array}{c}\text { Mean } \\
\text { Square }\end{array}$} & F & Sig. \\
\hline \multirow{2}{*}{$\begin{array}{l}\text { Regression } \\
\text { Residual }\end{array}$} & 850,764 & 2 & 425,382 & 26,280 &, $000^{\mathrm{b}}$ \\
\multicolumn{1}{|c|}{ Total } & 2080,937 & 76 & 16,186 & & \\
\hline
\end{tabular}

a. Dependent Variable: AKHLAK

b. Predictors: (Constant), POLA ASUH DEMOKRATIS, PAI 
Dari data diatas peneliti dapat melihat apakah variabel independen secara simultan (bersama-sama) mempengaruhi secara signifikan dengan variabel independen. Namun sebelum peneliti mengetahui hasil dari data diatas maka agar lebih mempermudah peneliti membuat hipotesis sebagai berikut:

Ho : tidak ada pengaruh yang signifikan antara variabel independen secara simultanatau bersama-sama dengan variabel independent

$\mathrm{Ha}$ : ada pengaruh yang signifikan antara variabel independen secara simultan atau bersama-sama dengan variabel independent

Agar lebih mudah bagi peneliti untuk melakukan analisis data diatas peneliti menggunakan kriteria pengujian sebagai berikut:

Ho : diterima apabila nilai signifikan $>0,05$

Ho : ditolak apabila nilai signifikan $<0,05$

Data diatas menunjukkan bahwa nilai signifikan adalah 0,000 yang mana $0,000<0,05$ hal ini berarti Ho ditolak dalam artian bahwa ada pengaruh yang signifikan antara variabel independen( $\mathrm{X} 1$ dan $\mathrm{X} 2)$ secara simultan terhadap variabel $\mathrm{Y}$, atau bisa lebih diperjelas bahwa menurut data diatas bahwa Pendidikan Agama Islam dan Pola Asuh orangtua Demokratis mempengaruhi terhadap akhlak secara bersamasama(simultan).

Coefficients $^{\mathrm{a}}$

\begin{tabular}{|c|c|c|c|c|c|}
\hline \multirow[t]{2}{*}{ Model } & \multicolumn{2}{|c|}{$\begin{array}{c}\text { Unstandardized } \\
\text { Coefficients }\end{array}$} & $\begin{array}{c}\text { Standardized } \\
\text { Coefficients }\end{array}$ & \multirow[t]{2}{*}{$\mathrm{t}$} & \multirow[t]{2}{*}{ Sig. } \\
\hline & B & $\begin{array}{l}\text { Std. } \\
\text { Error }\end{array}$ & Beta & & \\
\hline (Constant) & 68,763 & 9,667 & & 7,113 & , 000 \\
\hline $\begin{array}{l}\text { Pendidikan } \\
\text { Agama Islam }\end{array}$ & ,308 & ,055 & 497, & 5,636 & ,000 \\
\hline $\begin{array}{l}\text { Pola Asuh } \\
\text { Demokratis }\end{array}$ & 237, & ,050 & ,418 & 4,736 & 000, \\
\hline
\end{tabular}

a. Dependent Variable: AKHLAK

Dari data diatas peneliti dapat melihat apakah variabel independen secara parsial (masing-masing) mempengaruhi secara signifikan dengan variabel independen. Namun sebelum peneliti mengetahui hasil dari data diatas maka agar lebih mempermudah peneliti membuat hipotesis sebagai berikut:

Ho : tidak ada pengaruh yang signifikan antara variabel independen secara parsial atau bersama-sama dengan variabel independent

$\mathrm{Ha}$ : ada pengaruh yang signifikan antara variabel independen secara parsial atau bersama-sama dengan variabel independent 
Agar lebih mudah bagi peneliti untuk melakukan analisis data diatas peneliti menggunakan kriteria pengujian sebagai berikut:

Ho : diterima apabila nilai signifikan $>0,05$

Ho : ditolak apabila nilai signifikan $<0,05$

Data diatas menunjukkan bahwa nilai signifikan baik X1(PAI)dan $\mathrm{X} 2$ (Pola asuh orangtua demokratis)adalah 0,000 yang mana $0,000<0,05$ hal ini berarti Ho ditolak dalam artian bahwa ada pengaruh yang signifikan antara variabel independen(X1 dan X2)secara parsial terhadap variabel $\mathrm{Y}$, atau bisa lebih diperjelas bahwa menurut data diatas bahwa Pendidikan Agama Islam dan Pola Asuh orangtua Demokratis mempengaruhi terhadap akhlak secara parsial(masing-masing).

\section{Analisis koefisien determinasi (R Square)}

\section{Model Summary}

\begin{tabular}{|l|r|r|r|r|}
\hline Model & R & R Square & $\begin{array}{c}\text { Adjusted R } \\
\text { Square }\end{array}$ & $\begin{array}{r}\text { Std. Error of } \\
\text { the Estimate }\end{array}$ \\
\hline 1 &, $639^{\mathrm{a}}$ &, 409 &, 393 & 4,023 \\
\hline
\end{tabular}

a. Predictors: (Constant), POLA ASUH DEMOKRATIS, PAI

Berdasarkan tabel diatas.diketahui bahwa hasil perhitungan $\mathrm{R}^{2}$ sebesar 0,409 yang berati bahwa 40,9\% akhlak remaja dipengaruhi oleh pendidikan agama islam dan pola asuh orang tua demokratissedangkan sisanya sebesar 59,1\% dipengaruhi oleh faktor lain yang tidak diteliti disini.

\section{PEMBAHASAN}

Dalamhasilpenelitiantelahdisampaikanhasilanalisisstatistikpengaruh Pendidikan Agama Islam dan pola asuh orang tua demokratis terhadap akhlak remaja baik secara parsial maupun secara simultan. Dari hasil statistic tersebut di sini perlu dibahas kaitannya dengan uji hipotesis dan kajian teoritis.

Uji t digunakan untuk menguji pengaruh variabel bebas terhadap variabel terikat secara parsial dengan cara merujuk $t$ hitung terhadap $t$ tabel bila $t$ hitung lebih besar dari tabel berarti ada pengaruh variabel bebas terhadap varibel terikat. Hipotesis pertama, diduga ada pengaruh yang positif Pendidikan Agama Islam terhadap akhlak remaja di lingkunganmasyarakat Desa Sumbermulyo Kecamatan Jogoroto Kabupaten Jombang. 
Berdasarkan hasil analisis pada tabel diatas diperoleh $\mathrm{t}$ hitung sebesar 5,636 bila dirujuk dengan nilai t tabel pada taraf signifikasi $5 \%$ diperoleh nilai t tabel sebesar 1,67 sehingga t hitung lebih besar dari $t$ tabel $(5,636>1,67)$ maka hasilnya signifikan. Dengan demikian dapat disimpulkan bahwa ada pengaruh positif yang signifikan antara Pendidikan Agama Islam terhadap akhlak remaja di lingkungan masyarakat Desa Sumbermulyo Kecamatan Jogoroto Kabupaten Jombang.

Hipotesis kedua, diduga ada pengaruh yang positif pola asuh orang tua demokratis terhadap akhlak remaja di lingkungan masyarakat Desa Sumbermulyo Kecamatan Jogoroto Kabupaten Jombang. Berdasarkan hasil analisis pada tabel diatas diperoleh $t$ hitung sebesar 4,736bila dirujuk dengan nilai t tabel pada taraf signifikasi $5 \%$ diperoleh nilai $\mathrm{t}$ tabel sebesar 1,67 sehingga $\mathrm{t}$ hitung lebih besar dari $\mathrm{t}$ tabel $(4,736>1,67)$ maka hasilnya signifikan. Dengan demikian dapat disimpulkan bahwa ada pengaruh positif yang signifikan antara pola asuh orang tua demokratis terhadap akhlak remaja di lingkungan masyarakat Desa Sumbermulyo Kecamatan Jogoroto Kabupaten Jombang.

Hipotesis tiga, diduga ada pengaruh yang positif Pendidikan Agama Islam dan pola asuh orang tua demokratis terhadap akhlak remaja di lingkungan masyarakat Desa Sumbermulyo Kecamatan Jogoroto Kabupaten Jombang.Uji $\mathrm{F}$ dimaksudkan untuk mencari pengaruh secara simultan antara X1 dan X2 danterhadap Y hasil SPSS dapat dilihat pada tabel berikut ini

ANOVA $^{\mathrm{a}}$

\begin{tabular}{|c|c|c|c|c|c|}
\hline Model & $\begin{array}{l}\text { Sum of } \\
\text { Squares }\end{array}$ & $\mathrm{Df}$ & $\begin{array}{l}\text { Mean } \\
\text { Square }\end{array}$ & $\mathrm{F}$ & Sig. \\
\hline Regression & 850,764 & 2 & 425,382 & 26,280 &, $000^{\mathrm{b}}$ \\
\hline Residual & 1230,173 & 76 & 16,186 & & \\
\hline Total & 2080,937 & 78 & & & \\
\hline
\end{tabular}

a. Dependent Variable: AKHLAK

b. Predictors: (Constant), POLA ASUH DEMOKRATIS, PAI

Berdasarkan perhitungan tabel diatas diperoleh hasil $\mathrm{F}$ hitung sebesar 26,280sedangkan $\mathrm{F}$ tabel dengan signifikansi $5 \%$ adalah 3,10 yang berarti $26,280>3,10$ sehingga hipotesis dapat diterima yang berarti ada pengaruh signifikan antara Pendidikan Agama Islam dan pola asuh orang tua demokratis terhadap akhlak remaja di lingkungan masyarakat Desa Sumbermulyo Kecamatan Jogoroto Kabupaten Jombang.

Hal ini menunjukkan bahwa kontribusi pola asuh demokratis terhadap akhlak remaja cukup tinggi dibanding dengan pola asuh yang 
lain. Temuan ini sesuai dengan teori yang ada yang mengatakan bahwa pola asuh demokratis merupakan pola asuh yang paling tinggi levelnya. Pola asuh demokratis dikatakan paling tinggi levelnya karena dalam pola asuh ini orang tua memberi kondisi yang sehat bagi perkembangan konsep diri anak sehingga anak dapat berperilaku positif, karena anak berada pada kondisi yang kondusif.

Dalam penelitian ini tingkat pendidikan agama orang tua memiliki kontribusi yang paling besar dibanding dengan pola asuh orang tua, hal ini sesuai dengan teori yang dikemukakan Munandir bahwa kepribadian dan tingkah laku orang itu, lebih merupakan hasil belajar dari pada hasil pembawaan dari lahir. ${ }^{15}$ Maksud belajar di sini adalah belajar meniru/modelling dari orang tua dalam hal beragama. Selain itu juga sesuai dengan teori yang dikemukakan oleh Daradjat yang mengatakan bahwa kemerosotan moral biasanya disertai oleh sikap menjauh dari agama. ${ }^{16}$

Temuan penelitian ini memperlihatkan bahwa pola asuh orang tua dan pendidikan agama islam mempunyai kontribusi secara signifikan terhadap perkembangan akhlak remaja, terutama pola asuh demokratis dan pendidikan agama islam yang memberikan sumbangan cukup besar terhadap akhlak remaja.

\section{KESIMPULAN DAN SARAN}

Berdasarkan hasil penelitian dan pengelolahan hasil penelitian yang telah diuraikan sebelumnya, maka kesimpulan penelitian ini dapat dikemukakan bahwa, (1) terdapatpengaruh yang positif Pendidikan Agama Islam terhadap akhlak remaja di lingkungan masyarakat Desa Sumbermulyo Kecamatan Jogoroto Kabupaten Jombang. Berdasarkan hasil analisis pada tabel diatas diperoleh t hitung sebesar 5,636 bila dirujuk dengan nilai t tabel pada taraf signifikasi $5 \%$ diperoleh nilai t tabel sebesar 1,67 sehingga thitung lebih besar dari t tabel (5,636 >1,67) maka hasilnya signifikan. Dengan demikian dapat disimpulkan bahwa ada pengaruh positif yang signifikan antara Pendidikan Agama Islam terhadap akhlak remaja di lingkungan masyarakat Desa Sumbermulyo Kecamatan Jogoroto Kabupaten Jombang; (2) terdapatpengaruh yang positif pola asuh orang tua demokratis terhadap akhlak remaja di lingkungan masyarakat Desa Sumbermulyo Kecamatan Jogoroto Kabupaten Jombang

\footnotetext{
15 Munandir, Program Bimbingan Karir di Sekolah. Jakarta: Departemen Pendidikan dan Kebudayaan Direktorat Jendral Pendidikan Tinggi, 1996

${ }^{16}$ Daradjat, Z, Ilmu Jiwa Agama, Jakarta: Bulan Bintang, 1989.
} 
Berdasarkan hasil analisis pada tabel diatas diperoleh $\mathrm{t}$ hitung sebesar 4,736bila dirujuk dengan nilai t tabel pada taraf signifikasi $5 \%$ diperoleh nilai t tabel sebesar 1,67 sehingga t hitung lebih besar dari $t$ tabel $(4,736>1,67)$ maka hasilnya signifikan. Dengan demikian dapat disimpulkan bahwa ada pengaruh positif yang signifikan antara pola asuh orang tua demokratis terhadap akhlak remaja di lingkungan masyarakat Desa Sumbermulyo Kecamatan Jogoroto Kabupaten Jombang terdapat pengaruh yang positif Pendidikan Agama Islam dan pola asuh orang tua demokratis terhadap akhlak remaja di lingkungan masyarakat Desa Sumbermulyo Kecamatan Jogoroto Kabupaten Jombang.Berdasarkan perhitungan tabel diatas diperoleh hasil F hitung sebesar 26,280sedangkan $F$ tabel dengan signifikansi $5 \%$ adalah 3,10 yang berarti 26,280>3,10 sehingga hipotesis dapat diterima yang berarti ada pengaruh signifikan antara Pendidikan Agama Islam dan pola asuh orang tua demokratis terhadap akhlak remaja di lingkungan masyarakat Desa Sumbermulyo Kecamatan Jogoroto Kabupaten Jombang.

Berkaitan dengan penelitian ini penulis memberikan saran:

1. Agar para guru dan orang tua di lingkungan masyarakat Desa Sumbermulyo Kecamatan Jogoroto Kabupaten Jombang.terus meningkatkan pendidikan agama islam baik secara formal maupun nonformal dengan baik agar menghasilkan peningkatan mutu akhlak remaja yang sangat signifikan

2. Agar para orang tua di lingkungan masyarakat Desa Sumbermulyo Kecamatan Jogoroto Kabupaten Jombang terus meningkatkan pola asuh demokratis dengan baik agar menghasilkan peningkatan mutu akhlak remaja yang sangat signifikan

3. Untuk para pembaca khususnya para Guru, Orang tua, para pecinta pendidikan dan siswa baik di di lingkungan masyarakat Desa Sumbermulyo Kecamatan Jogoroto Kabupaten Jombang ataupun daerah lain hasil penelitian ini tentunya dapat sebagai acuan untuk lebih meningkatkan Pendidikan Agama Islam beserta pola asuh demokratis agar dapat menjadikan akhlak remaja semakin meningkat. 


\section{DAFTAR PUSTAKA}

Bambang Prasetyo, Metode Penelitian Kuantitatif, (Jakarata: PT Raja Grafindo Persada, 2008)

Bukhari Umar, Ilmu Pendidikan Islam, (Jakarta: AMZAH, 2010),

Daradjat, Z, Ilmu Jiwa Agama, Jakarta: Bulan Bintang, 1989.

Depag RI, Al-Qur'an Dan Terjemahnya,(Jakarta: PT. Qomari Prima.2002)

Hidayah, Nur., Pengarub Pola Asub Orang Tua Terhadap Pembentukan Kepribadian, (Jakarta: Bumi Aksara,2012)

M. Kasiram, Metodologi Penelitian Pendidikan, (Jakarta: Rineka Cipta, 2006)

Munandir, Program Bimbingan Karir di Sekolah. Jakarta: Departemen Pendidikan dan Kebudayaan Direktorat Jendral Pendidikan Tinggi, 1996

Mursidin, Akblak Sumber Pendidikan, (Bandung : PT Ghalia Indonesia, 2011)

Sugiyono, Metode Penelitian Kualitatif, Kuantitatif, R\&D, (Bandung: Alfabeta, 2016)

Syofian , statistik parametrik untukpenelitian kuantitatif, (Jakarta: Bumi Aksara, 2016)

Wajidi Sayadi, Hadits Tarbawi,(Jakarta: PT. Pustaka Firdaus.2009)

Zakiah Daradjat,Pendidikan Islam Dalam Keluarga dan Sekolah,(Jakarta : Ruhama, 1995) 
Abidatul Mardliyah 